\title{
The Exploration of PBL Applied in Experimental Medical Statistics Teaching
}

\author{
Ling $\mathrm{QI}^{1, \mathrm{a}}$, Hong-ling ZHANG ${ }^{2, \mathrm{~b},{ }^{,}}$Xin $\mathrm{WANG}^{3, \mathrm{c}}$ and Jing WANG ${ }^{4, \mathrm{~b}}$ \\ ${ }^{1,2,3}$ School of Health Science and Nursing Wuhan Polytechnic University, \\ Wuhan, China \\ ${ }^{4}$ Key Laboratory of Applied Psychology Chongqing Normal University, \\ Chongqing, China \\ aqiolive_23@163.com, bzhlwjb@sina.com, c'wangxin_244@hotmail.com \\ dwangjingsyxy@163.com \\ ${ }^{*}$ Corresponding author
}

Keywords: PBL, Medical statistics, Experimental teaching model.

\begin{abstract}
PBL(Problem Based Learning) is the problem based learning, with the introduction of experimental teaching practice into "medical statistics", it helps to break the traditional experimental teaching exercises class limitations, and using actual source material to stimulate students' enthusiasm and initiative, improve students' knowledge and ability to analyze and solve problems, improve the efficiency of the classroom; meanwhile it will reflect on the issues of the students' Autonomous learning, teacher preparation, classroom organization and time management, teaching content suitability and other issues of reflection.
\end{abstract}

\section{Introduction}

Medical statistics is a medical science theory, with the help of statistical principles and methods of medical phenomena in the data collection, collation, analysis and inference of an applied discipline [1], it is one of the basic courses in non-preventive medicine. This subject has a great significance to cultivate students' scientific thinking ability, improve their ability of analyzing and solving problems. As an important part of this course, experimental teaching plays an irreplaceable role in guiding students to link statistical theory with medical clinical research, to stimulate students 'interest, and promote students' flexible application of theoretical knowledge to solve practical problems. However, the vast majority of medical colleges and universities to set up the medical statistics internship is basically a "exercises", that is materials or instruction manual exercises and explanations in the main, difficult to stimulate student initiative and enthusiasm, so that it is difficult for the teaching reform to exert its true value. Therefore, how to improve the quality of experimental teaching and improve the students' understanding of medical statistics knowledge and the ability to use in scientific research is the focus and difficulty in the experimental teaching reform.

In recent years, the introduction of PBL (Problem-based learning) teaching theory from abroad has provided a new way of thinking, which is based on questions, students as the main body, in the form of group discussions, with the participation of tutors, a topic or problem analysis, is a problem-oriented teaching methods, is a student-centered education [2]. The research proves that PBL teaching method can help the students lay a flexible knowledge foundation, cultivate the ability of critical thinking and creative thinking, cultivate the ability of independent study and solve practical problems [3]. 
Therefore, PBL teaching method has become one of the most popular international teaching methods, according to WHO report around the world more than 1,700 medical schools have adopted PBL teaching model, this figure is still increasing. At the same time, some domestic medicine institutions have also carried out the PBL teaching, and gradually become a model of medical education reform of a trend [4]. We try to apply PBL theory to the experimental teaching of medical statistics in the course of rehabilitation therapy (this lesson), explore and optimize the current experimental teaching methods, and improve the quality of experimental teaching.

\section{Exploring Experimental Teaching Reform Based on the Theory of PBL}

Based on PBL, We will reform from the teaching content, teaching methods and evaluation three aspects.

\section{Teaching Content Reform}

The introduction of PBL theory can solve the single problem of current experimental teaching mode. The traditional experimental teaching mainly focuses on exercises in teaching materials or instruction manuals, emphasizing on the use and explanation of individual statistical methods. Students often only need to apply the formula to solve the problem, which can only improve the students' mechanical application formula ability, the ability of students to use the comprehensive application of statistical theory of knowledge has not been a real exercise; At the same time, as the existing teaching materials and guide manual exercises are mostly used for many years of classic cases, it is lack of typical cases for different medical students, and the actual clinical problems encountered in scientific research vary widely, it is difficult to stimulate student interest and initiative. Therefore, in the existing experimental teaching conditions, the introduction of PBL teaching method, the first problem is that, PBL is the problem-centered teaching methods, and then the medical statistics experimental teaching links "problem" come from? We mainly through the following three ways to solve this problem: (1) the use of domestic and foreign recently published high-quality academic articles to set the problem; (2) the combination of social hot spots, such as "hollow" design issues; (3) to mobilize students, combined with other course learning, to increase part of the experimental design, such as rehabilitation research and innovation, students interested in research topics selected from the problem. This will solve the problem of PBL in the source, but also makes the teaching content with the actual clinical research, social hot issues and students 'own interests combined to improve students' initiative and enthusiasm, to help students form a holistic research thinking, Students use the theory of statistical knowledge to provide material.

\section{Teaching Methods Reform}

The traditional teaching methods of experimental teaching are mostly arranged by the teacher, the students complete the exercises independently, and then the teacher's comment way, teachers are still the core of the classroom, This teaching methods lack of interaction between teachers and students, students and students, it is difficult for students in such teaching model to improve the analysis of problems and problem-solving capabilities. PBL teaching theory emphasizes the students as the main body, in the form of group discussions of educational methods. Therefore, we try to do the following reforms for experiment teaching methods: (1) 6-8 students as a group, one week in advance, the teacher will design a good case to the students, and provide some 
relevant references for it; (3) the practice class has the students to report, the teachers for the students to learn, discuss and report the situation outlined, and further put forward new issues; (4) the practice of the students in the class, the students can use the time to collect information and discuss; (5) consider the limited time, the second discussion of the results, the group submitted in writing, and then teachers to sum up again. The group will give written report, and then the teacher will give conclusion.

\section{Evaluation Mode Reform}

Traditional experimental teaching is actually practice, no separate assessment, it is difficult to play the role of experimental teaching to improve the ability of students to analyze and solve problems, it is difficult to attract the attention of students and difficult to stimulate students' learning enthusiasm and initiative. Therefore, the combination of PBL teaching model, we have made the following changes in the assessment of experimental teaching: (1) to increase the proportion of experimental teaching in the entire course of assessment (30\%); (2) the use of analytical published data (as well as the national data published by the WEBCOM website and the data published in the academic articles), the students are required to carry out statistical analysis and design according to the questions.(3) By setting up the form of "everyone to review manuscripts", we choose the public to publish the article data, and let the students as the "reviewer" point out the shortcomings and mistakes of the design idea, the implementation process and the statistical analysis methods.

\section{The Experience and Thinking of PBL Teaching Method in Teaching}

PBL teaching model takes students as the main body, problem-oriented to group discussions and mutual learning as the main form, very popular with the students. We have accumulated some experience and understanding in the teaching application.

\section{The Experience of PBL Teaching Method}

PBL Teaching Method can Help to Improve Classroom Teaching Efficiency. With the development of curriculum reform and the effectiveness of classroom teaching, the pursuit of efficient classroom has become the goal of teachers to work together. With the popularization of network information, students gain more knowledge and information, and the time of teachers' "information authority" has long ceased to exist. The traditional teaching of "full house" can not meet the teaching needs in the new period [5]. PBL teaching emphasizes students' extra-curricular learning, independent learning, teachers in the pre-class design problems, students use extra-curricular time to collect data, group discussions, to achieve the learning and teaching center of gravity forward, help to improve classroom teaching efficiency.

PBL Teaching Method can Help to Improve the Students' Enthusiasm. The problem is the core of PBL teaching method, combined with social hotspots and professional characteristics to design problem, embodies the "learn and have to teach" advanced teaching ideas. Through the problem, so that students are looking forward to the learning content, help to change the textbook examples is not targeted, not closely linked with the students, It is difficult to stimulate the enthusiasm of students to learn the limitations, improve the initiative of students' independent learning. Through pre-class group discussions, some problems can be resolved before class, help students to analyze problems and solve practical problems, while through solving problems, the students can also gain confidence. 
PBL Teaching Method Help Promote the Emotional Exchange between Teachers and Students. PBL teaching through the set of challenging issues, so that teachers and students and among the students the cooperation, exchange and interaction become the norm, while breaking the traditional university teachers and students is limited to classroom communication limitations, students can at any time after school "Problems" with teachers to discuss and exchange. At the same time, the implementation of PBL teaching is based on student discussion and reporting, teachers play the role of guide, further dilute the teacher "classroom authority", classroom teaching content, student activities interspersed, so that students can free to express their views and ideas, in a more pleasant, relaxed learning atmosphere to feel the joy of solving problems and a sense of accomplishment.

\section{PBL Teaching Methodology}

Higher Demands on Teachers. PBL teaching methods put forward higher requirements for teachers to prepare lessons, classroom time management and organizational capacity than the traditional classroom. In preparing lessons, teachers not only need familiar with the content of the professor, but also need to understand the content of the front-line knowledge, familiar with the textbooks on the basis of good, but also need to repeat reviewing the literature, familiar with the relevant background knowledge and cutting-edge development, especially on problem design, It is necessary to meet the learning objectives, reflecting the learning content, but also make the problem to fully mobilize the enthusiasm of the students, the difficulty should be appropriate. The classroom teaching, due to student discussions, reports and teacher summary and other links, so teachers should have the ability to detect problems, guide the problem, a variety of teaching activities also require teachers to have a good classroom organization and time control ability.

Higher Requirements of Students Self-learning Ability. PBL emphasizes student-centered teaching, requiring students to spend a lot of time outside the classroom to collect data, conduct group discussions, and complete the preparation of relevant content. This teaching method is more suitable for higher self-learning ability students, and for those who are accustomed to teaching students have some difficulty, its own initiative is difficult to get full play. $[6,7]$ Therefore, how to strengthen the guidance and management of the classroom for the further development of PBL teaching is placed in front of a key issue for teachers.

Teaching Content Suitable Problem. PBL teaching method requires students to have basic knowledge and a certain degree of self-learning ability, and because each case of teaching compared to traditional teaching methods need to spend more time, which for the current lack of time, students of heavy school situation, Not suitable for all. Compared with theoretical teaching, PBL teaching method may be more suitable for experimental teaching. Medical statistics theory teaching is mainly teaching of the basic concepts and theories of medical statistics, these elements is quite difficult for student without advanced mathematics and probability of statistical rounds basic, while using of PBL teaching method, it is not easy for students to produce fear, will affect students' initiative and initiative.

PBL teaching method is a student-oriented, problem-oriented, student self-learning and mutual discussion and teachers interspersed teaching method. This method can maintain the classroom atmosphere active, stimulate student learning initiative, training students analysis of issues ability, such as verbal expression comprehensive ability. 
However, this teaching method also puts forward higher requirements to the quality of teachers and students, and does not apply to all teaching contents.

\section{Acknowledgement}

This research was financially supported by the Education research from Educational Department of Wuhan Polytechnic University. (ID: XQ2015008)

\section{References}

[1] Yong-yong Xu, Zhen-qiu Sun. Medical Statistics (in Chinese). People's Medical Publishing House, 2002.

[2] Zhen-jiang Hou, Xiao Wang, Xiu-ling Qi,el. The current situation analysis of PBL teaching pattern applied in China's medical education (in Chinese). Medical Information, 01 (2010) 23-25.

[3] M.Silvia, H.G. Schmidt, G. Norman. Innovations in Problem - based Learning: What can we Learn from Recent Studies. Advances in Health Sciences Education, 11(2006) 397-402.

[4] E.A. Farmer. Faculty development for problem-base learning. Eur J Dent Educ, 02(2004):59-66.

[5] Zhi-hong Zhang, Shao-long Lin, Xiao-Kang Zhu, el al. Evaluation of the effectiveness of "the teaching-based-on-learning model "applied in medical statistics teaching(in Chinese). China Medical Education Technology.20 (2014)39-41.

[6] Guang-you Li, Zhang Lei. The exploration of PBL in medical statistics teaching (in Chinese).Journal of educational institute of Jilin province. 06(2013)53-55.

[7] Xiao-yang Cui, Li Yi, Liao Hu, el al. The application and problems of PBL in China's medical education (in Chinese). Researches in Medical Education.04 (2010) 439-442. 